\title{
Agronomy, sustainability and good agricultural practices
}

\author{
Jean-Pierre CALIMAN ${ }^{1}$ \\ André BERTHAUD ${ }^{2}$ \\ Bernard DUBOS ${ }^{3}$ \\ Bertrand TAILLIEZ ${ }^{3}$ \\ ${ }^{1}$ P.O. Box 1348, 28000 Pekanbaru Riau, \\ Indonesia \\ $<$ jean-pierre.caliman@cirad.fr> \\ 2 Ed. Gato Pardo 300N, Avenida Gonzalez \\ Suarez N32-12, Quito, Ecuador \\ ${ }^{3}$ Boulevard de La Lironde, TA 80/PS3, \\ 34398 Montpellier Cedex 05, France
}

Since the beginning of the 20th century, oil palm cultivation has developed in successive waves, driven by the enthusiasm of farmers, of the pre- or post-colonial local authorities, and of certain major development companies, firstly in tropical and equatorial Africa, from where the oil palm originates, then in Latin America and Southeast Asia. In Southeast Asia, yields have increased from a few hundred tonnes of oil per hectare in the 1920s [1], to more than $7.5 \mathrm{t}$ of palm products/ha mentioned quite frequently today, which are average figures that are sometimes recorded on areas amounting to tens of thousands of hectares. Such a performance is the result of ongoing improvements, be it to cultural techniques, the genetic characteristics of the seeds used, the effectiveness of crop protection, or CPO and palm kernel oil extraction techniques.

For many decades, cropping system sustainability was ensured by careful and wise management based on the know-how and rationality of smallholders. On estate plantations or at national smallholder assistance centres, it sometimes led to formalized instructions or agricultural practice guides.

The experimental and scientific approach proposed by agricultural research has gradually contributed to the development and economic sustainability of the system ([2]: special report entitled "Recherches agronomiques pour le développement et durabilité" OCL, vol. 5, $\mathrm{n}^{\circ} 2$ March/April 1998), even in very critical situations where such sustainability has had numerous occasions to be questioned [3]. On the other hand, the example of Latin American

\begin{abstract}
Sustainable palm oil production needs to be based on the application of a code of good practices, respecting a certain number of criteria related to economic, environmental and social aspects. We focus here on economic and environmental aspects, attempting to take stock of the current situation regarding the management of inputs (fertilizers, pesticides), and of oil mill waste (empty fruit bunches, effluent). We also take a look at the main agricultural research required if we are to be able to assess the situation on different scales and see how it is evolving, and also provide assistance for rational management that is compatible with farmers' production targets.
\end{abstract}

Key words: oil palm, sustainability, mineral nutrition, agricultural waste, soil fertility

plantations devastated by bud rot, although exceptional, helps us to keep in mind the potential dangers of the systems that have been developed.

The definition of sustainability recently took on an environmental dimension and a social dimension that were not previously taken into account in agricultural guides/instructions unless they had a direct short-term impact on the economic sustainability of the activity in question. Increasing pressure from NGOs and consumers for sustainable development in all 3 of its dimensions is leading the oil palm industry to revise its farming system towards rational management of cultural practices, requiring sometimes significant changes in farmer attitudes, and why not in the planting systems themselves.

This pressure has led to recent initiatives in the profession and the creation in 2003 (legally in April 2004) of a round table on sustainable palm oil production (see article $\mathrm{H}$. Omont in this $O C L$ issue), acknowledging the potential risk of a major impact associated with this crop that is specific to fragile ecological and social zones.

The first meeting of the round table (Kuala Lumpur, Malaysia, 2003) provided an opportunity to start defining sustainability for palm oil and compiling a code of good practice to be applied throughout the production chain. The second meeting (Jakarta, Indonesia, 2004) launched work to define sustainability criteria that will have to be respected by all those working in sectors covered by the round table. These criteria, listed in the appendix A, notably include several principles relative to respecting legal, economic, technical, environmental and social aspects, plus a further chapter specific to setting up new plantations.

Among the criteria presented, the "long-term maintenance and improvement of soil fertility" is undoubtedly the one that has attracted the greatest attention during the development of this crop worldwide, be it from farmers or researchers. However, although the need to improve soil protection on slopes is universally acknowledged, it has not been systematically applied, probably because it usually requires additional investment when the plantation is set up, at a time when funding is more difficult to find.

The other agronomic criteria do not appear to be followed with the same intensity or uniformity, depending on the farmers or the criteria, as we shall see later in this article.

We shall attempt to assess the situation in terms of specifically agronomic and agrienvironmental aspects; the other aspects will be covered in other articles to appear in this issue of OCL. We shall also attempt to determine what agricultural research is required to ensure success.

\section{Good agricultural practices}

The first reaction when aspiring to sustainable production, irrespective of the limits of its definition, consists in applying "good" agricultural practices.

As already mentioned in the introduction, when oil palm cultivation began, these good agricultural practices consisted in careful and 
wise management designed to pass down a fertile and productive production tool to future generations, by virtue of the knowledge, knowhow and, sometimes maybe, the very instinct of the farmer.

With the development of "estate" plantations, these practices often became formalized by way of manuals describing the different production techniques, the purpose of which was to standardize practices within estates and "guarantee" optimum productivity, hence economic sustainability.

Logically speaking, this aspect amounts to criterion 3.1. of the technical component proposed by the members of the round table (see Appendix A): "Plantation and mill operating procedures are appropriately documented ...". These oil palm cultivation guides, which are often confidential inside each large private company, have been completed by numerous publications from international or local research and development organizations, in the form of agricultural practice-advice regularly updated as knowledge progresses and in line with the results of agricultural research. The monthly advice notes produced by IRHO (Institut de Recherches pour les Huiles et Oléagineux), which were launched in 1961, and subsequently published in several languages for more than thirty years, are the most comprehensive example [4, 5]. Technical datasheets published by national research centres are also intended to be ways of disseminating good agricultural practices, as are the handbooks published more recently [6-8].

It is important to note that even if direct reference to environmental impacts, as such, was only rarely made, many of the recommended cultural practices directly or indirectly incorporated aspects relative to reducing environmental risks. For instance, in the first half of the 20th century, it was possible to read how important it was to protect the soil with a legume cover crop after forest clearance when setting up plantations; so as to reduce the risks of erosion and improve soil fertility; there are therefore frequent references to land development measures on slopes, and practices to limit erosion and water runoff [9-12], etc.

The initiatives taken by the round table to promote systematic reference to a code of good practice are an important step and should also encourage organizations supervising local smallholders to take similar initiatives, so as to benefit from recommendations that enable them to more effectively preserve their family heritage.

\section{Rational input management}

\section{Maintaining soil fertility}

Managing the chemical fertility of soils by applying fertilizers is undoubtedly the aspect to which farmers have paid the greatest attention. However, it has to be acknowledged that the aim was essentially one of productivity (achieve maximum yields), environmental aspects, and the conservation of natural resources being totally absent from the initial considerations.

Nowadays, despite knowing more about how oil palms function, and the better means of communication and improved dissemination of knowledge, it is still often found that numerous plantations do not have a fertilization plan worthy of that knowledge. This is undoubtedly due to the fact that oil palms make use of substantial amounts of fertilizer, product prices have been generally favourable, with relatively short periods of tension, masking any mistaken management with excessive inputs.

Yet rational input management, specifically mineral fertilizers, ought to be a priority for farmers, since it is so true that it generally results in higher profitability, whilst having a positive impact on the environment and on natural resources. Its feasibility and efficacy, which are based on field trials, the monitoring

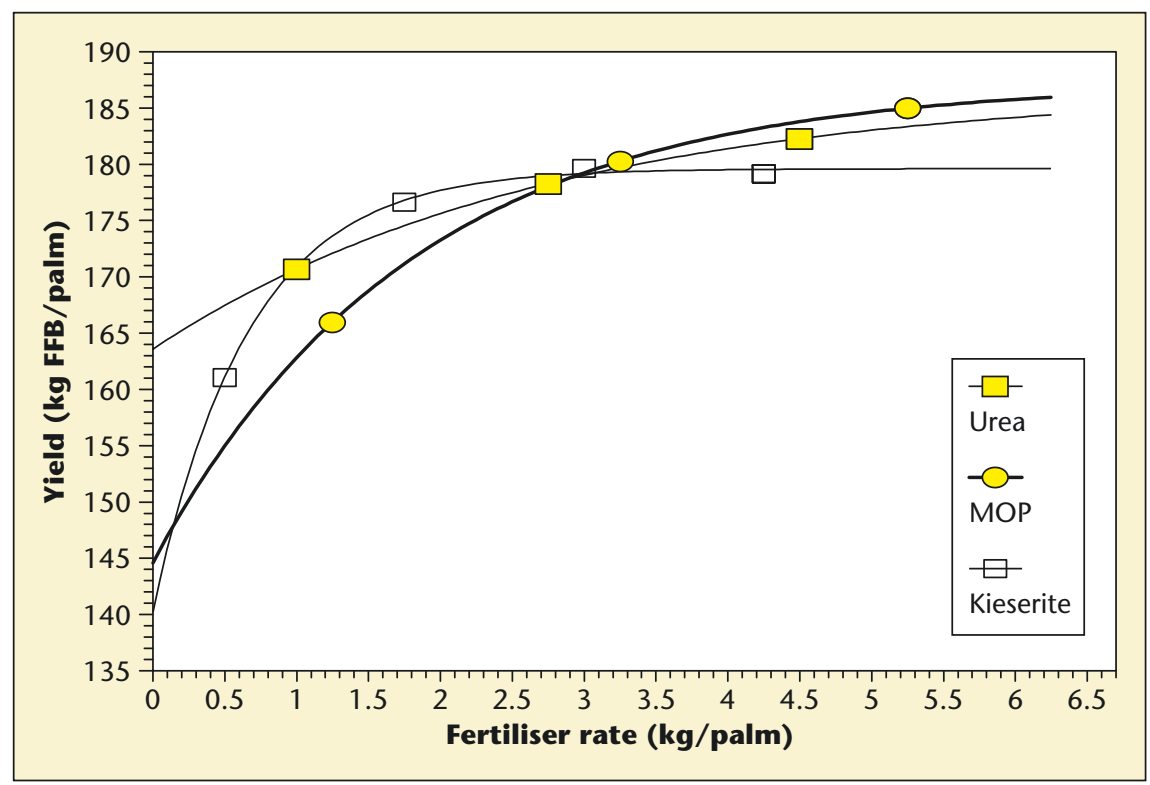

Figure 1. North Sumatra. Yield response to fertiliter rates. Curves showing the response of oil palms to urea, potassium and kieserite applications. On smallholdings with low inputs, preference should be given to potassium applications (moderate rate), kieserite (low rate), then urea (moderate rate). (From Caliman et al., 2001).

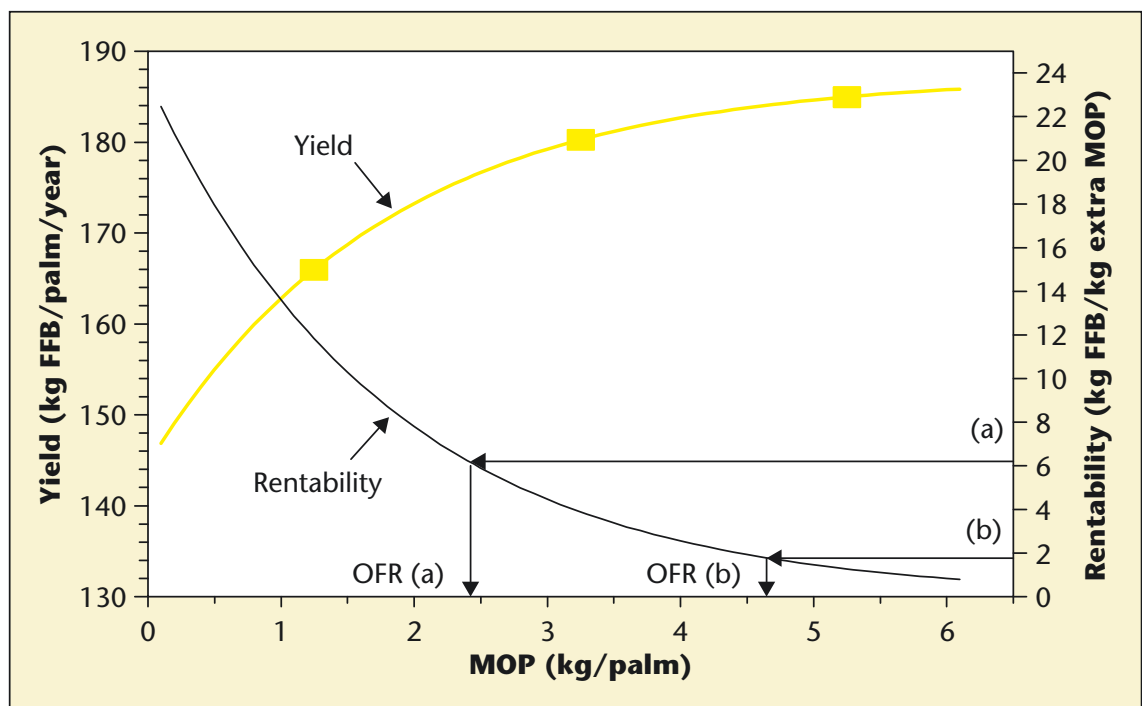

Figure 2. Yield response curve and MOP economical efficiency. Determining the fertilizer (potassium) application rate depending on the objectives fixed: profitability, yield level, etc. (From Caliman et al., 2001). 
of oil palm mineral nutrition, and good knowledge of the environment thereby enabling site specific management, have been demonstrated in many situations.

They have been reported in a certain number of publications [13-15]. The method is based on plotting curves to see how oil palm yields and leaf contents respond to the fertilizer rates applied (figures 1, 2, 3). A rational choice of input levels can then be made in line with the objectives fixed.

Its power even makes it a unique tool for drawing up recommendations for smallholdings (figure 1): the response curves drawn up for neighbouring large estates can be used to fix priorities, whether it be for choosing the fertilizer type, its formulation or the application rate in an environment as diversified as smallholdings.

It is therefore a veritable decision support method, by which adaptations can be made to both general and specific situations that involve both economic conditions (product value, fertilizer costs, cash-flow availability, etc.), farmers' production targets, and why not environmental considerations, by superposing an environmental risk curve (figure 4) derived from the difference between the calculated mineral nutrient requirements of the plant to ensure its growth and production, and the

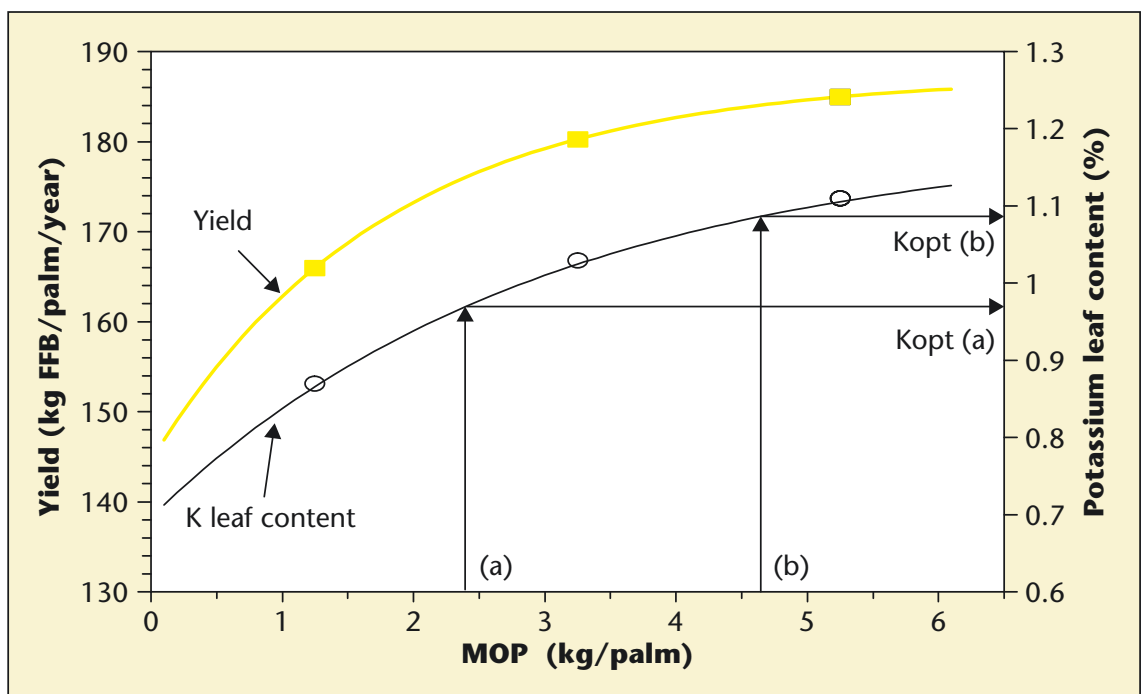

Figure 3. Yield and $K$ response curves $K$ optimum leaf content. Determining optimum leaf contents corresponding to the objectives fixed. (From Caliman et al., 2001).

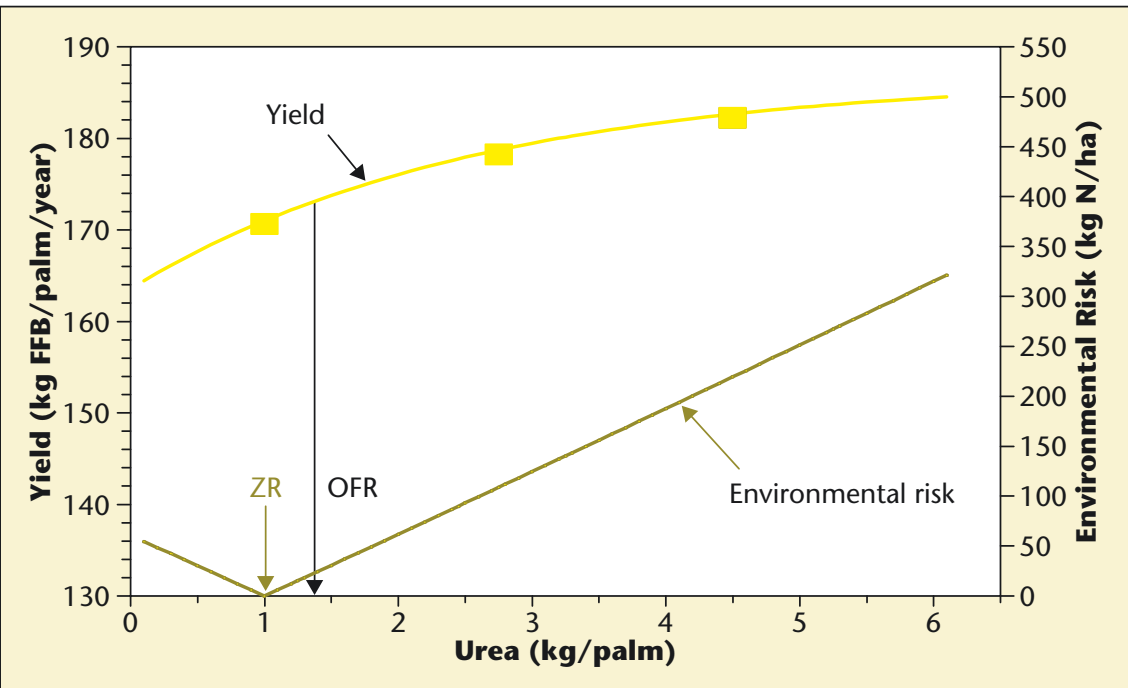

Figure 4. Yield response curve to urea rate and environnemental risk. ZR indicates the rate corresponding to theoretical environmental risk 0. (From Caliman et al., 2004).

nutrients actually provided by fertilization. This type of curve provides an opportunity for a first evaluation, at a very global scale, of the amount of nutrient that could be lost and would represent a danger for the environment, as well as for the natural resources. In the example shown figure 2, around $35 \%$ of the recommended rate of urea will be not be used by the palms to insure their performance. In fact part of this $\mathrm{N}$ excess might be uptaken by the palms as luxurious nutrition, while the remaining part will be lost either in the atmosphere through volatilisation and emission, or in surface and ground water through runoff and leaching, depending on the rainfall pattern.

The method also recommends five-yearly monitoring of chemical fertility levels in the soil, combining leaf analyses (LSU) and soil analyses (SSU). By monitoring in this way, it can be checked that the fertilization strategy is conducive to long-term maintenance, or improvement where necessary, of soil fertility levels.

\section{Managing agricultural waste}

Management of oil mill waste (empty bunches, effluents) has now joined mineral nutrition and soil fertility management.

This waste comes in considerable volumes, with one tonne of empty fruit bunches (EFB) and almost 3 tonnes of effluent for each tonne of crude palm oil produced. For environmental reasons, their treatment and application in plantations have gradually replaced EFB incineration, or effluent discharges into rivers. In some countries, such as Ecuador, no new mills can be constructed without a prior environmental impact study. Temporary mill closures have even been reported, following operating faults in effluent treatment systems.

The mineral characteristics of these by-products mean that they can be used to replace mineral fertilizers. Moreover, organic material in EFB form can be used to improve soils physically (improved infiltration speed [16]), chemically and biologically, notably in low-fertility zones (sandy soils improved by repeated EFB applications).

A good understanding of mineral nutrient release rates from EFB has made it possible to achieve a level of rational management, with true incorporation of their use in oil palm fertilization plans (figures 5, 6). Thus, application rates and frequencies, but also levels of supplementary mineral fertilization where necessary, can be rationally established in line with environmental conditions and the status of the palms.

Likewise, it is necessary to have a clear understanding of the biological impact of those applications. For example, it has led to applications being halted in immature plantings in African 


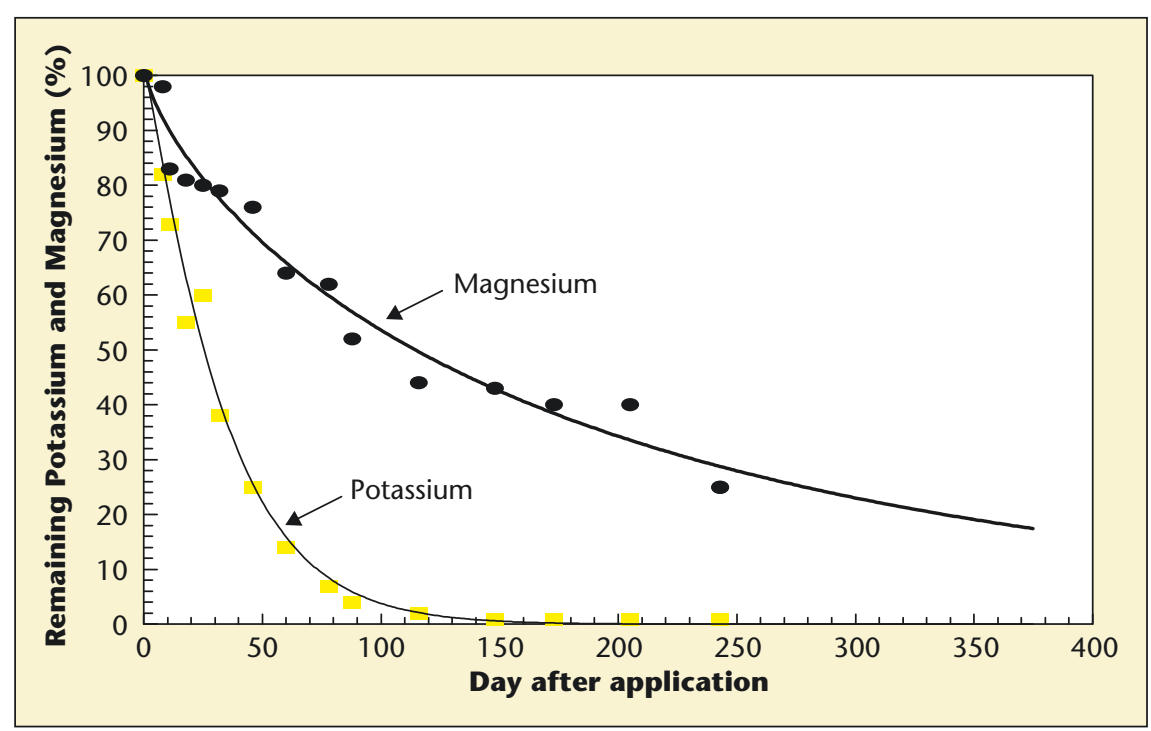

Figure 5. Dynamic of $\mathrm{K}$ and $\mathrm{Mg}$ release from EFB after field application. $90 \%$ of potassium is released in the 3 months following EFB application in the field. (From Caliman et al., 2004).

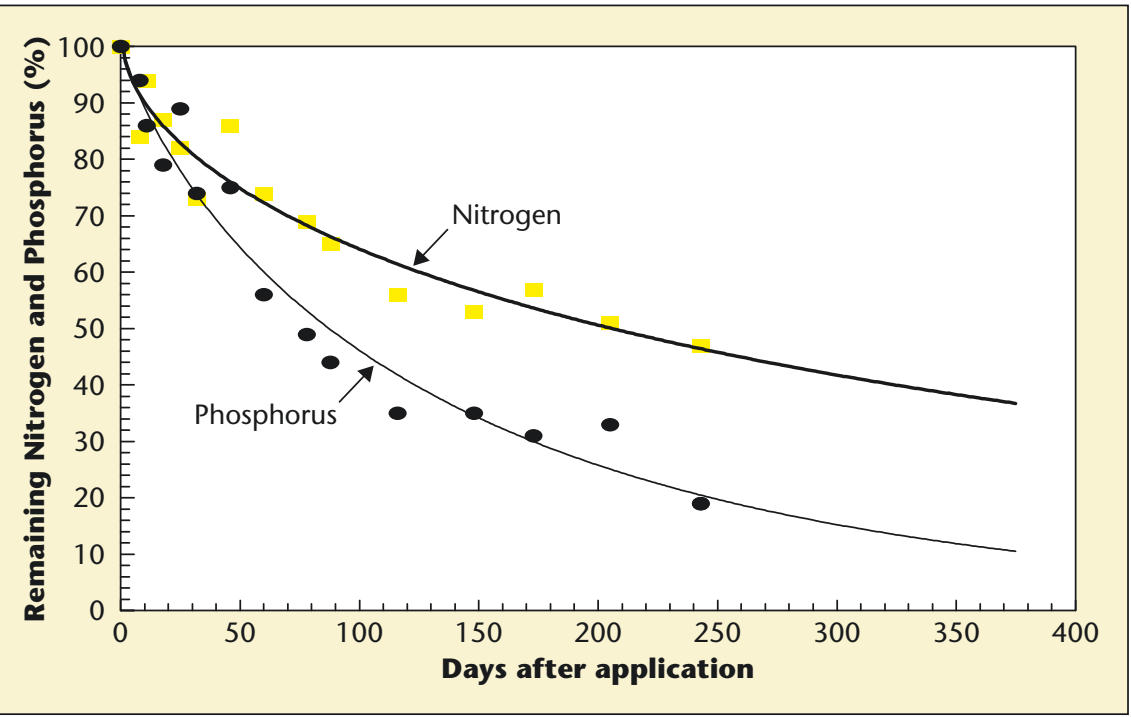

Figure 6. Dynamic of $N$ and P release from EFB after field application. 60\% of nitrogen is released in the 12 months following EFB application in the field. (From Caliman et al., 2004).

regions affected by vascular wilt. In the Llanos region of Colombia, field application is banned for part of the year to prevent the proliferation of a fly that goes on to attack the livestock of neighbouring cattle farmers.

Effluent management has yet to reach such a sophisticated degree of management. This is no doubt partly due to the considerable volumes involved, and to the "liquid" state of the product, which not only calls for relatively more difficult application systems, but also for water and mineral balances that bring into play water flow considerations in addition to mine-

\section{Controlling diseases and pests}

Pesticide use is also an essential concern when considering good agricultural practices. The situation is highly contrasted, with:

- on the one hand, crop protection from pests largely bringing into play IPM, with consequent minimum use of pesticides.

Host plants of predatory insects are frequently planted on the edge of plots and receive particular attention (figure 7). Although their efficiency sometimes remains to be confirmed, it reveals a general intent that is worth mentioning. In Latin America, many estates even allow a certain woody regrowth to develop in interrows not used for transport, also to encourage beneficial insect life (figure 8 ).

- and on the other hand, weed control largely based on intensive herbicide use, in most Southeast Asian estates, but also on smallholdings in the same region. For instance, soils that have become virtually bare are often seen in oil palm plantations due to the intensive and often abusive use of herbicides, even on moderate to steep slopes with dramatic consequences for erosion. This phenomenon appears to be less intense in Africa, and especially in Latin America, where woody regrowth is judiciously managed, as already mentioned.

Hence these estates in Southeast Asia developed over tens of thousands of hectares, which have not used any insecticides in 2004, whereas herbicide use, all commercial products combined, reached 1 litre/ha on average in the same year.

It has to be said that predators have relatively little effect on oil palm cultivation, especially in Southeast Asia, less so in Africa and Latin America, and that the main diseases that develop in Asia (Ganoderma), Africa (vascular wilt) and Latin America (bud rot) do not lend themselves to chemical treatment, either due to the lack of an effective molecule against the disease (soilborne fungi), or due to physical difficulties associated with the crop itself: its perennial nature and intense root development preventing soil treatment. Consequently, attempts at control are focusing on agronomic, and especially genetic aspects (search for genes of resistance).

mineral balance remains excessive, hence the environmental situation is not totally satisfactory.

The technique more recently developed for by-product composting [17-19] appears to be very attractive for treating and simultaneously making use of all these by-products (EFB, effluents, and why not fibres and kernel cake where necessary). Yet so far, it remains virtually unadopted by farmers, despite the undeniable technical and economic advantages it offers.

\section{Sustainability and agricultural research}

Should current farming systems be totally called into doubt, in favour of purely organic farming for example, or can they be rationalized, from the launching of new projects right up to the management of plantations once they have been created? 


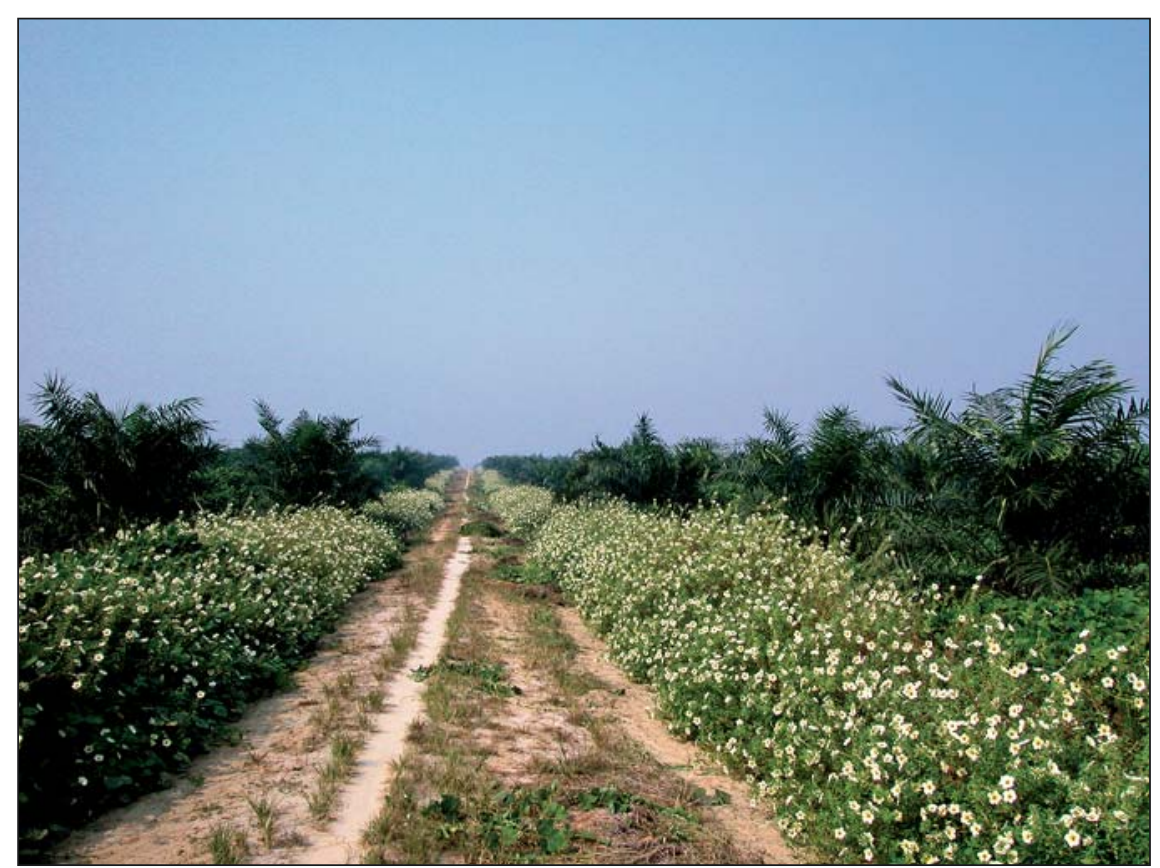

Figure 7.

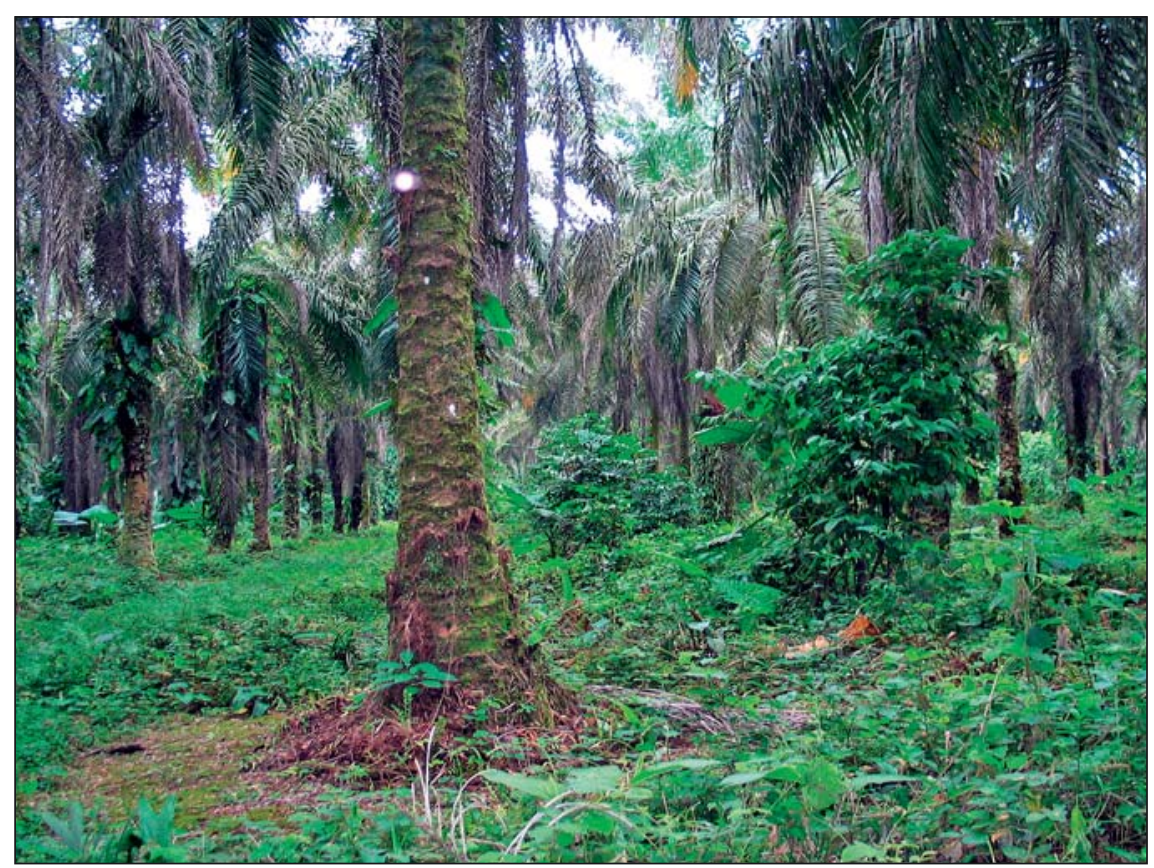

Figure 8.

Today, one of the main questions is to know whether agricultural research will be able to tackle the concerns associated with sustainable oil palm development. In the two situations just mentioned, a total rethink of the farming system i.e. organic farming system (although its development will most probably be limited, as related to specific market), or its rational management, agricultural research needs to play a large role, in order to provide strong scientific backing prior to any cultural decision. Indeed, in the first example of organic agriculture, particular care needs to be taken to ensure that there is no loss of fertility in the environment. This can only be validated through studies of short, medium and long-term mineral balances. But it is then also necessary to ensure that fertility is not maintained by a simple geo- graphical or "social" transfer of fertility (case of agricultural populations directly or indirectly "selling" their organic matter for income).

In the case of rational farming system management, agricultural research needs to acquire sufficiently fine-tuned knowledge of how the plant and the environment function, and of their interaction, so as to be able to propose agricultural practices and management tools enabling production targets to be reached that are eco-friendly and compatible with the preservation of natural resources.

After supplying farmers with a good practice guide, then defining the criteria for sustainable palm oil production, it is essential to develop indicators capable of assessing the impact that any cultural practice might have either on the environment or on the crop itself. These agrienvironmental indicators, as defined by OECD [20-22] need to provide information on the status of each situation, monitor the progress achieved, and thereby cover all the agronomic aspects associated with oil palm cultivation. If they are to be validated, they need to be built on sound scientific foundations, which means improving knowledge, as already stated.

For instance, studies on mineral nutrient cycles, the establishment of short, medium and longterm mineral balances, knowledge of the bioavailability of nutrients in the soil, but also of how the plant functions, are essential for rationally managing the mineral nutrition of oil palms in their environment. Better knowledge of the specificity of each type of planting material is needed, so as to match input management to it as closely as possible, and cover the plant's requirements, whilst taking the capacity of the environment into consideration.

Assessing the environmental risks associated with oil mill by-product management is another challenge that should lead on to the definition of optimum conditions for applying effluents or other by-products (EFB, compost) in accordance with the pedoclimatic properties of each situation. Another necessity is to assess the biodegradability of by-products such as effluents depending on soil characteristics.

The impact of natural cover crops (woody regrowth or others) in oil palm plantations needs to be carefully studied, to determine how they are involved in mineral nutrient cycles and in the water cycle, but also their true impact on biodiversity in several of these aspects (plant and animal), as their influence is no doubt not limited merely to serving as a host plant for certain predators.

It is therefore a new challenge that awaits agricultural research that once again amounts to "how to produce, but how to produce better". 


\section{Appendix A. RSPO Criteria for sustainable palm oil production}

(See www.sustainable-palmoil.org for updates)

\section{A.1. Principle 1: Compliance with applicable laws and regulations}

Criterion 1.1 There is compliance with all applicable local, national and ratified international laws and regulations

Criterion 1.2 The right to use the land can be demonstrated

Criterion 1.3 The right to the land does not diminish the legal or customary rights of other users

\section{A.2. Principle 2: Management planning that aims to achieve long-term economic and financial viability for plantation and mills \\ Criterion 2.1 Optimal productivity and quality of produce is achieved on planted land through appropriate agronomic and management practices Criterion 2.2 Plantation and mill practices are optimal to maintain production of high quality CPO}

\section{A.3. Principle 3: Use of appropriate best practices in plantations and mills}

Criterion 3.1 Plantation and mill operating procedures are appropriately documented and consistently implemented and monitored

Criterion 3.2 Practices must maintain, and if necessary, improve, soil fertility at a level that ensures high and sustained yield

Criterion 3.3 Practices must minimise and control erosion and degradation of soils

Criterion 3.4 Practices must maintain the quality and quantity of surface and ground water

Criterion 3.5 Pests, diseases, weeds and invasive introduced species are effectively managed whilst pesticide use is minimised through using appropriate Integrated Pest Management (IPM) techniques

Criterion 3.6 Pesticides banned by national legislation shall not be used and any other herbicides and pesticides should be used in a way that does not endanger health or environment

Criterion 3.7 The on and off-site impacts of the plantation and mill management activities should be adequately assessed, controlled and monitored

Criterion 3.8 An assessment of the social impacts, both positive and negative, of proposed operations in existing plantations is carried out and the results are incorporated into management planning and implemented in operational procedures

Criterion 3.9 There is appropriate implementation of occupational health and safety requirements

Criterion 3.10 All staff, workers and smallholders are adequately trained and competent

\section{A.4. Principle 4: Environmental responsibility and conservation of natural resources and biodiversity}

Criterion 4.1 An understanding of the plant and animal species and habitats that exist inside and around the plantation shall be established

Criterion 4.2 A plan to conserve and restore biodiversity in and around the plantation shall be developed, implemented and monitored

Criterion 4.3 Waste from the plantation and the mill is reduced, recycled and re-used and any waste produced is disposed of in an environmentally and socially responsible manner

Criterion 4.4 Efficiency of energy use should be maximised whilst minimising fossil fuel use

Criterion 4.5 Use of fire for waste disposal and for preparing land for replanting is avoided except in exceptional circumstances and should always be consistent with the ASEAN Policy on Zero Burning

Criterion 4.6 Plans to reduce pollution and emissions, including greenhouse gases, should be developed, implemented and monitored

\section{A.5. Principle 5: Responsible consideration of employees and of individuals and communities affected by} plantations and mills

Criterion 5.1 There is an effective, open and transparent method for communication and consultation between companies, local communities and other affected or interested parties

Criterion 5.2 There is a documented system for dealing with complaints and grievances which is implemented and effective

Criterion 5.3 Any negotiations concerning compensation for loss of legal or customary rights should be dealt with through a documented system that enables local communities and other stakeholders to express their views through their own representative institutions or other forms of collective bargaining Criterion 5.4 All workers have acceptable pay

Criterion 5.5 All workers have acceptable conditions and the rights of workers to voluntarily organise and negotiate with their employers shall be guaranteed Criterion 5.6 Child labour is not used unless children are involved as part of small family owned and run enterprises and under adult supervision or an integrated education programme

Criterion 5.7 Plantations and mills deal fairly and transparently with smallholders and other local businesses

Criterion 5.8 Plantations and mills contribute to local development wherever possible

\section{A.6. Principle 6: Commitment to continual improvement in all areas of activity}

Criterion 6.1 Plantation companies should regularly monitor and review their activities and develop and implement action plans that ensure continual improvement in all operations

\section{A.7. Principle 7: Responsible development of new plantations}

Criterion 7.1 A comprehensive assessment of impacts or formal environmental impact assessment shall be undertaken prior to establishing new plantations or expanding existing ones and the results incorporated into plans and operations

Criterion 7.2 Soil and topographic surveys and site planning should be conducted prior to the establishment of plantations and the results of these should be incorporated into plans and operations

Criterion 7.3 Primary forest and any area containing one or more High Conservation Values must not be converted to plantation

Criterion 7.4 Extensive planting on steep, marginal and fragile soils is avoided

Criterion 7.5 A comprehensive, participatory social impact assessment is carried out for all new plantings and the results are incorporated into all planning and operations

Criterion 7.6 No plantations shall be established on indigenous peoples' land without their free, prior and informed consent as expressed through their own representative institutions

Criterion 7.7 Customary rights and sacred sites are recognised and respected

Criterion 7.8 Local people are fairly compensated for land acquisitions

Criterion 7.9 Use of fire in the preparation of new plantations is avoided other than in specific situations that are consistent with the ASEAN Policy on Zero Burning

\section{A.8. Principle 8: Commitment to transparency}

Criterion 8.1 Plantation managers should provide full information to other stakeholders, except where this is prevented by commercial confidentiality or where disclosure of information would result in negative environmental or social outcomes 


\section{REFERENCES}

1. BOUTIN D. Indonésie : près d'un siècle de plantations de palmier à huile. OCL 1998; 5(2) : 110-2.

2. OCL. Dossier : Recherches agronomiques pour le développement et durabilité. OCL 1998 ; 5(2).

3. CALIMAN JP, AUBRY M. Passé et avenir du palmier à huile dans la savane de Dabou (Côte d'Ivoire). OCL 1998 ; 5(2) : 113-5.

4. CIRAD. Agricultural Practices Oil Palm. IRHO Advice - Volume 1. Paris : CIRAD.

5. CIRAD. Agricultural Practices Oil Palm. IRHO Advice - Volume 2. Paris : CIRAD.

6. RANKINE I, FAIRHURST T. Field handbook. Oil palm series - Volume 1. Nursery, 1998.

7. RANKINE I, FAIRHURST T. Field handbook. Oil palm series - Volume 2. Immature, 1998.

8. RANKINE I, FAIRHURST T. Field handbook. Oil palm series - Volume 3. Mature, 1998.

9. CALIMAN JP, DE KOCHKO P. A few crop techniques and special improvements on oil palm plantations to limit erosion and water runoff. Oléagineux 1987 ; 42(3). Agricultural Practice IRHO Advice 275 : 100-6.
10. CALIMAN JP, AUBRY M. Description of a simplified technique for setting up an oil palm plantation along contour lines. Oléagineux 1992; 47(11). Agricultural Practice - IRHO Advice $333: 661-70$.

11. QUENCEZ P. The use of fronds to control erosion in oil palm plantations. Oléagineux 1986 ; 41(7). Agricultural Practice - IRHO Advice No. $268: 315-20$

12. KEE KK, SOH AC. Management of oil palms on slopelands in Malaysia. IOPRI International Palm Oil Conference. 08-12 July 2002. Bali. Indonesia.

13. CALIMAN JP, DANIEL C, TAILLIEZ B. Oil palm mineral nutrition. Plantations, recherche, développement $1994 ; 1$ (3/93) : 36-54.

14. CALIMAN IP, HARDIANTO I, NG MILTON. Strategy for fertilizer management during low commodity prices. PORIM International Palm Oil Congress. 20-23 August 2001. Kuala Lumpur. Malaysia.

15. CALIMAN JP, DUBOS B, TAILLIEZ B, ROBIN P, BONNEAU $X$, BARROS I. Manejo de nutricion mineral en palma de aceite: Situation actual y perspectivas. Palmas 2004 ; Vol. 25, No especial, Tomo1 : 42-60.
16. CALIMAN JP. BUDI MARTHA, SALETES S. Dynamics of nutrient release from empty fruit bunches in field conditions and soil characteristic changes. PORIM International Palm Oil Congress. 20-23 August 2001. Kuala Lumpur. Malaysia.

17. SIREGAR FA, SALETES S, CALIMAN JP. LIWANG T. Empty bunch compost : processing and utilities. IOPRI International Palm Oil Conference. 08-12 July 2002. Bali. Indonesia.

18. LORD S, HOARE MK, THOMPSON NM. Composting for zero discharge - NBPOL's solution. IOPRI International Palm Oil Conference. 08-12 July 2002. Bali. Indonesia.

19. SCHUCHARDT F, DARNOKO D. PURBOYO GURITNO. Composting of empty fruit bunches (EFB) with simultaneous evaporation of oil mill waste water (POME). IOPRI International Palm Oil Conference. 08-12 July 2002. Bali. Indonesia.

20. OECD. Towards sustainable development. Environmental indicators. 1998.

21. OECD. Environmental indicators for agriculture. Volume 2 : Issues and design. 1999.

22. OECD. Environmental indicators for agriculture. Volume 3 : Methods and results. 1999. 